\title{
Use of multiple causes of death in the analysis of occupational cohorts-an example from the oil industry
}

\author{
Lesley Rushton
}

\begin{abstract}
Objectives-To examine the efficacy of routine examination of multiple causes of death occurring on death certificates in cohort studies, with an example from the oil industry.

Methods-The underlying and multiple causes were coded for all notified deaths from a cohort of 35000 men employed at eight oil refineries in the United Kingdom. Matrices of the frequencies of underlying causes by contributory causes were analysed for the total population and by subgroups defined by refinery, occupation, age, and calendar period of death.

Results-Over $75 \%$ of the 10128 certificates had two or more causes but this varied by disease. Many ratios of mentions of total to underlying causes were similar to those of England and Wales. Ratios for cancer of the larynx and pneumonia were lower, indicating possible over-reporting of these diseases as the underlying cause. Investigation of an excess of pneumonia deaths at one refinery indicated possible miscoding of the underlying cause or the wrong position of pneumonia on some certificates, particularly in combination with malignancy and stroke.
\end{abstract}

Conclusions-Routine analysis of multiple causes of death can provide useful additional information in cohort studies.

(Occup Environ Med 1994;51:722-729)

Keywords: mortality, multiple cause, cohort study, petroleum refining

This paper investigates the use of analysis of multiple causes of death in the context of occupational health, with an example from the oil industry. The importance of examining contributory causes (CC) in addition to, and in combination with the underlying cause (UC) is emphasised to aid the interpretation of results, and to identify causal associations. The uses of multiple causes as an indication of morbidity and to identify cases for nested case-control studies are also discussed.

Much information on the interrelation of the other diseases involved in death is discarded if only the UC of death is examined. Alderson suggested that multiple cause coding ${ }^{1}$ - that is, coding of the UC and all other diseases mentioned on the certificate
(CC) - could be used (a) to pinpoint causes of death that are often the only cause mentioned, $(b)$ to identify UCs where these are lost to the dominant cause when this takes precedence at the time of death, (c) to identify associated diseases. The importance of the consideration of data on CCs in estimating the impact of chronic diseases has been recognised. ${ }^{2-5}$

Guralnick suggested the assessment of whether a particular combination of UCs and CCs reflected concomitant disease processes or whether they arose out of random occurrence of separate disorders. ${ }^{5}$ The need for more uniformity in the completion of death notifications and the description of disease has been identified. ${ }^{67}$ Future changes in International Classification of Diseases (ICD) codes could be contemplated so that some of the understatement of disease caused by use of the UC only would be removed. ${ }^{8}$ Wong et al suggested similarly that a matrix of primary causes by CCs could be used to give an overall picture of mortality patterns. ${ }^{9}$ This would serve as a scheme to identify disease combinations, and be used as a data editing device, for example by identifying unexpected ICD codes. They also suggest that the ratio of the total number of times a cause is coded (TC), to the number of times it appears as the UC gives an indication of those causes that are under-represented if the analysis is based on the UC only. A ratio substantially $>1$ might imply under-reporting of the condition as the UC. The ratios may be affected by the age distribution of the population where coding differences occur at different age groups; for example, there is a tendency not to report arteriosclerosis as a UC for younger age groups. ${ }^{10}$ Wong et al suggested that a possible use of the ratios might be to compare the ratios before contrasting mortality patterns of sets of data where the rules used by nosologists may differ. ${ }^{9}$ They also suggested that the ratio could be used to screen for situations where comparisons based on the primary cause would be misleading. The result of the comparison of observed and expected deaths may be affected if the ratio of TCs:UCs is large, especially for rare diseases where the number of observed deaths is small. None the less, comparison of UCs with rates of an external population may be valid if the ratios are similar for the two populations. The ratio of TCs:UCs mentioned has been used in several studies to examine the magnitude of the additional deaths not attributed to the UC. ${ }^{11-14}$ 
Multiple cause coding is not generally available but has been carried out for deaths in England and Wales from samples of death certificates in 1972-4 and from all certificates for $1975,1976,1985$, and 1986 . Hence, there is scope for exploiting this in occupational studies.

Limitations of mortality statistics must be considered in any analysis of data from death certificates. In the United Kingdom death certification has been compulsory since 1836 and is thought to be comprehensive. ${ }^{1}$ Inaccuracy of causes of death may occur at four stages of the process of certification: $(a)$ at diagnosis, $(b)$ on completion of the certificate, $(c)$ on classification of the UC, and $(d)$ in coding. Several studies have examined the accuracy of diagnostic information at time of death. Some have compared the clinical diagnosis with necropsy diagnosis. ${ }^{15-17}$ Other studies have compared death certificates with reviews of detailed case histories. ${ }^{18} 19$

This paper examines the efficacy of routine examination of multiple causes of death that occurred on death certificates in cohort studies. The following sections report analyses by numbers of causes recorded, and the distribution of UCs for specific diseases, age, date of death, and occupation. The association of particular diseases is examined with $\chi^{2}$ tests. Comparisons are made with national data where possible. There are a few discrepancies between the coding used for the study and the national populations. When the cohort was first analysed (to 1975) ${ }^{20}$ the death certificates were coded to be comparable with the death rates for England and Wales provided by Case et al. ${ }^{21}$ This was continued in the second follow up to provide continuity with the first reports. ${ }^{22}$ The few differences between the Case coding and current practice are commented on in the text.

\section{Method}

In almost all studies of occupational cohorts, use is made only of the UC of death recorded on the certificate. This paper reports an analysis of the multiple causes recorded on the death certificates of a cohort of 35000 men employed for at least one year between 1 January 1950 and 31 December 1975 at eight oil refineries in the United Kingdom. In this paper the refineries are referred to as $A, B, C$, $D, F, G, H$, and J. The background to the study and the results of analyses by UCs have been reported elsewhere, for the first follow up to the end of $1975,{ }^{20}$ and the second follow up to the end of $1989 . .^{22}{ }^{23}$ Deaths up to the end of 1989 are included in this paper.

The UC and up to three other causes were coded. There were very few certificates with more than three other causes. I coded deaths in the first follow up to the end of 1975 to the ICD-8, under the supervision of the late Professor Michael Alderson. In the second follow up death certificates were received from the Office of Population Censuses and Surveys (OPCS), already multiple cause coded to the appropriate revision. The coding rules specified in the ICD volumes were followed. Where more than three CCs were mentioned, generally, the first three were coded, with those in part I taking precedence over those in part II. The exception was if a malignancy was mentioned when this was always included. The term CC refers to any condition on the certificate other than the UC. Conditions other than the UC in part I and any mentioned in part II of the certificate are not distinguished under the general heading CC. There was relatively little change between the ICD-8 and 9 but any disparities were taken into account by standard bridging codes to ensure continuity of classification of diagnosis.

\section{Results}

NUMBERS OF CAUSES RECORDED

In previous studies of multiple causes on samples of death certificates, the percentage of certificates with two or more causes has varied from $50-80 \% .{ }^{38}$ Table 1 gives the distribution of the number of causes on certificates for the eight refineries and the total study population. Overall $75 \%$ of the certificates had two or more causes. Although the distribution over the number of causes for the eight refineries, which were situated in various parts of the United Kingdom (including two in Scotland) was broadly similar, a few differences are notable. Refineries B and D had a smaller proportion of certificates with only one cause and a larger proportion with four or more causes. Refinery C shows the opposite pattern. This may reflect differences in age distributions between the refineries, as B and D had older workforces and $\mathrm{C}$ a younger workforce. An increase in the number of causes mentioned as age of death increases has been reported. ${ }^{24}$ The higher proportion of certificates in refinery $\mathrm{G}$ with only one cause may be due to sampling variation, as this refinery contributed only very small numbers to the study. The percentage of certificates that reported only one cause varied greatly by the disease group (table 2) from none for diabetes and hyperplasia of the prostate, under $10 \%$ for hypertensive disease and bronchitis, from $20-30 \%$ for many of the malignant neoplasms and cardiovascular disease groups, to around $40 \%$ for malignant neoplasms of the oesophagus, lung, and brain, and $51 \%$ for leukaemia.

Table 1 Percentage of refinery study death certificates by number of causes mentioned on death certificates

\begin{tabular}{llllrl}
\hline \multicolumn{6}{l}{ No of causes on death certificate } \\
\cline { 2 - 6 } Refinery & 1 & 2 & 3 & $>4$ & Total $(n)$ \\
\hline A & $22 \cdot 1$ & $47 \cdot 7$ & $20 \cdot 1$ & $10 \cdot 1$ & $100 \cdot 0(434)$ \\
B & $20 \cdot 1$ & $43 \cdot 7$ & $23 \cdot 6$ & $12 \cdot 6$ & $100 \cdot 0(1470)$ \\
C & $27 \cdot 4$ & $40 \cdot 9$ & $23 \cdot 7$ & $8 \cdot 0$ & $100 \cdot 0(709)$ \\
D & $18 \cdot 1$ & $46 \cdot 3$ & $24 \cdot 3$ & $11 \cdot 3$ & $100 \cdot 0(1180)$ \\
F & $21 \cdot 9$ & $46 \cdot 2$ & $23 \cdot 2$ & $8 \cdot 7$ & $100 \cdot 0(1793)$ \\
G & $33 \cdot 6$ & $32 \cdot 8$ & $27 \cdot 0$ & $6 \cdot 6$ & $100 \cdot 0(122)$ \\
H & $24 \cdot 0$ & $44 \cdot 3$ & $22 \cdot 5$ & $9 \cdot 2$ & $100 \cdot 0(1181)$ \\
J & $24 \cdot 9$ & $46 \cdot 0$ & $20 \cdot 3$ & $8 \cdot 8$ & $100 \cdot 0(3239)$ \\
Total & $22 \cdot 9$ & $45 \cdot 1$ & $22 \cdot 3$ & $9 \cdot 7$ & $100 \cdot 00$ \\
(n) & $(2322)$ & $(4567)$ & $(2261)$ & $(978)$ & $(10128)$ \\
\hline
\end{tabular}

Counts of different causes in the same group of diseases, and nature of injury codes are included. 
Table 2 Number of certificates with a disease mentioned as the UC, CC, and TC, ratio of TCs:UCs for the total study population and for England and Wales 1986, and total number of conditions on certificates with disease groups as UC

\begin{tabular}{|c|c|c|c|c|c|c|c|}
\hline \multirow[b]{3}{*}{ Disease group } & \multicolumn{3}{|c|}{ Number of deaths } & \multirow[b]{3}{*}{$T C$} & & & \multirow{3}{*}{$\begin{array}{l}\text { Total number of } \\
\text { conditions on } \\
\text { certificates with } \\
\text { disease group as UC }\end{array}$} \\
\hline & \multirow[b]{2}{*}{$U C$} & \multirow{2}{*}{$\begin{array}{l}\text { From certificates } \\
\text { with only } \\
1 \text { cause } \\
\text { recorded (\%) }\end{array}$} & \multirow[b]{2}{*}{$C C$} & & \multicolumn{2}{|c|}{ Ratio of TCs:UCs } & \\
\hline & & & & & Study & $\begin{array}{l}\text { England and Wales } \\
1986(T C)\end{array}$ & \\
\hline $\begin{array}{l}\text { TB respiratory system } \\
\text { Malignant neoplasms: }\end{array}$ & 29 & 31 & 23 & 52 & $1 \cdot 79$ & $2 \cdot 46(611)$ & 54 \\
\hline Oesophagus & 104 & 42 & 9 & 113 & 1.09 & $1.08(2839)$ & 170 \\
\hline Stomach & 302 & 29 & 14 & 316 & 1.05 & $1.08(6419)$ & 548 \\
\hline Intestine & 186 & 17 & 18 & 204 & $1 \cdot 10$ & $1 \cdot 14(5768)$ & 369 \\
\hline Rectum & 126 & 17 & 13 & 139 & $1 \cdot 10$ & $1 \cdot 17(3644)$ & 251 \\
\hline Liver and gall bladder & 47 & 23 & 93 & 140 & 2.98 & $1 \cdot 26(1370)$ & 86 \\
\hline Pancreas & 110 & 30 & 6 & 116 & 1.05 & $1.06(3120)$ & 204 \\
\hline Larynx & 26 & 27 & 2 & 28 & $1 \cdot 08$ & $1 \cdot 27(844)$ & 50 \\
\hline Lung & 1032 & 38 & 31 & 1063 & 1.03 & $1.05(26596)$ & 1786 \\
\hline Prostate & 171 & 16 & 32 & 203 & $1 \cdot 19$ & $1 \cdot 22(8434)$ & 348 \\
\hline Bladder & 98 & 24 & 14 & 112 & $1 \cdot 14$ & $1.23(3915)$ & 189 \\
\hline Kidney & 56 & 21 & 8 & 64 & $1 \cdot 14$ & $1 \cdot 16(1602)$ & 107 \\
\hline Brain & 74 & 41 & 4 & 78 & 1.05 & $1.05(1432)$ & 124 \\
\hline Leukaemia & 68 & 51 & 12 & 80 & $1 \cdot 18$ & $1 \cdot 25(2407)$ & 111 \\
\hline Diabetes & 66 & 0 & 192 & 258 & 3.91 & $3.05(10565)$ & 173 \\
\hline Anaemia & 19 & 21 & 55 & 74 & 3.89 & $3.47(1626)$ & 39 \\
\hline Cerebrovascular disease & 854 & 30 & 211 & 1065 & 1.25 & $1 \cdot 38(37653)$ & 1577 \\
\hline \multicolumn{8}{|l|}{ Heart diseases: } \\
\hline Chronic rheumatic & 70 & 14 & 14 & 84 & $1 \cdot 20$ & $2.03(1391)$ & 154 \\
\hline Ischaemic & 3372 & 22 & 298 & 3670 & 1.09 & $1.46(129909)$ & 5935 \\
\hline Other & 231 & 21 & 1499 & 1730 & $7 \cdot 49$ & $8 \cdot 70(63074)$ & 427 \\
\hline Hypertensive disease & 110 & 6 & 290 & 400 & 3.64 & $7 \cdot 92(14651)$ & 256 \\
\hline Disease of arteries & 301 & 21 & 894 & 1195 & 3.97 & $3.34(28207)$ & 574 \\
\hline Other disease of circulatory system & 68 & 10 & 182 & 250 & 3.68 & $7 \cdot 76(7332)$ & 139 \\
\hline Pneumonia & 399 & 34 & 1092 & 1491 & 3.74 & $6 \cdot 20(62762)$ & 713 \\
\hline Bronchitis & 433 & 4 & 283 & 716 & 1.65 & $2.45(21553)$ & 902 \\
\hline Asthma & 26 & 15 & 22 & 48 & 1.85 & $1.88(1551)$ & 55 \\
\hline Peptic ulcer & 90 & 9 & 31 & 121 & $1 \cdot 34$ & $1 \cdot 61(3448)$ & 191 \\
\hline Cirrhosis of liver & 38 & 13 & 25 & 63 & 1.66 & $1.56(2191)$ & 82 \\
\hline Nephritis and nephrosis & 39 & 3 & 16 & 55 & 1.41 & $6 \cdot 37(2797)$ & 97 \\
\hline Hyperplasia of prostate & 28 & 0 & 15 & 43 & $1 \cdot 54$ & $1.94(1132)$ & 65 \\
\hline
\end{tabular}

FREQUENCY OF UNDERLYING AND CONTRIBUTORY CAUSES

Matrices of frequencies of UC (columns) by CC (rows) were tabulated for the refinery population. In these matrices, where more than one code from a disease group occurred, this has been counted only once in the matrix. The two disease groups where this occurred most often were ischaemic heart disease (ICD 410-4), and bronchitis (ICD 466, 490-2). In the ischaemic heart disease group the most common combination was myocardial infarction with coronary artery disease. In the bronchitis group the most common combination was chronic bronchitis with emphysema.

The row totals of the matrices give the number of certificates on which a specific diagnosis (including as a UC) was mentioned. The column totals give the number of conditions coded on certificates with a specific cause as the UC, and the diagonal elements give the number of certificates with the cause as the UC. Table 2 shows the row totals, column totals, and diagonal elements for selected causes of death, together with the ratios of TCs:UCs. For comparative purposes the ratio, together with the TCs, is also given for deaths of males in England and Wales 1986, ${ }^{25}$ as are the percentage of certificates where the UC was the only cause on the certificate.

There were a total of 10128 deaths where a death certificate was obtained, with a further 70 for whom the cause of death was unknown. Pneumonia, for example, was coded 1491 times, 399 times as the UC, when 314 various $C C$ were associated with them (not shown in table 2). These included 20 major malignancies, 34 cerebrovascular diseases, 17 ischaemic heart diseases, 45 other heart diseases, and 17 with bronchitis. The 1092 certificates with pneumonia as a CC included (not shown in table 2) 28 with stomach cancer as the UC, 137 with lung cancer as the UC, 198 with strokes as the UC, and 116 with bronchitis as the UC.

For many of the numerically large groups the ratios in table 2 for the study population and England and Wales are similar. Two exceptions are hypertensive disease and other diseases of the circulatory system. Hypertensive diseases may reflect differences in coding practices between the refinery study and OPCS; for example when hypertensive disease was linked by the fourth digit ICD code to other circulatory diseases it was coded again as a multiple cause by OPCS for England and Wales, but not in the refinery study.

The ratios for most of the malignant disease groups are close to unity in both the study population and the population from England and Wales, which indicates that these groups are, in general, reported as UCs. The exception is the high ratio for malignant neoplasm of the liver and gall bladder in the refinery study, which occurs partly because secondary liver neoplasms, and those where it is unknown whether they are primary or secondary, are included for the refinery group but not for England and Wales. The ratio for malignant neoplasm of the larynx is lower for the refinery population than for England and Wales. This could be due either to more reporting of this disease as a UC or underreporting as a CC in the refinery population. 
The ratios for many of the non-malignant disease groups tend to be larger than those for malignant disease in both populations, indicating an under-reporting of these conditions as UCs. I have already outlined the coding discrepancies in some of the heart disease groups which account for some of the differences between the ratios for the two populations. The ratio for pneumonia is much lower for the refinery population than for England and Wales, which again indicates a difference in the reporting of this disease as a UC between the two populations, in this case a relative over-reporting of pneumonia as a UC (or under-reporting as a CC) in the refinery population.

\section{DISTRIBUTION OF UNDERLYING CAUSE BY CONTRIBUTORY CAUSE \\ Malignant neoplasms}

Table 3 gives the distribution of the corresponding UCs for selected CCs. Malignant neoplasms in this table do not include "other malignant disease" because the individual diseases making up this group each contributed small numbers of deaths. Of the $174 \mathrm{CCs}$ of malignant neoplasms, $30 \%$ had a UC of another malignant neoplasm, $48 \%$ a UC of heart disease, mainly ischaemic heart disease, and $11 \%$ a UC of pneumonia. This last figure may reflect either a miscoding of the UC or the wrong position of pneumonia on the death certificate. Twelve of the 20 deaths with pneumonia as a UC and a malignant neoplasm as the CC occurred in one refinery, where an excess was found of observed deaths from pneumonia as a UC compared with those expected. ${ }^{22}$

Of the 276 CC malignant neoplasms 93 (34\%) were malignant neoplasm of the liver and gall bladder, most of these (74) had another malignant neoplasm as the UC. The UCs included 21 neoplasms of the stomach, 10 of the intestine, nine of the pancreas, and 13 of the lung. This again reflects the coding practice used in the study, as nearly all of the CC liver and gall bladder neoplasms were secondary, or unspecified as primary or secondary neoplasms.

\section{Diabetes}

Diabetes occurred on 258 certificates, 66 times as the UC. Table 3 shows that of the 192 deaths where diabetes was a CC, $19 \%$ occurred on certificates with cerebrovascular disease as the UC and $38 \%$ with ischaemic heart disease as the UC. The association of diabetes with cardiovascular and renal diseases both as the UC and as a CC has been previously shown. ${ }^{5}$ An examination of the association of death from diabetes with cerebrovascular and renal diseases in the refinery population showed that $4 \cdot 2 \%$ of the cases where cerebrovascular diseases were the UCs had diabetes as a CC compared with $1.7 \%$ of other UCs (significant $P<0.001$ ). There was, however, no association of diabetes with ischaemic heart disease in the refinery population.

\section{Cerebrovascular disease}

Table 3 shows the prevalence of the combinations of cerebrovascular disease as a CC with the heart disease groups as the UC, and the heart disease groups as a CC with cerebrovascular disease and other heart disease groups as the UC. In particular, a further examination of the association of cerebrovascular disease and ischaemic heart disease with diseases of the arteries showed that $18 \%$ of the cerebrovascular UCs had diseases of the arteries as a CC compared with $8 \%$ of other UCs, and $19 \%$ of ischaemic heart disease UCs had diseases of the arteries as CCs compared with $4 \%$ of other UCs (both significant $P<0.001$ ). An examination of the association between ischaemic heart disease and other heart and circulatory disease showed that $30 \%$ of the cases where ischaemic heart disease was the UC had other heart and circulatory disease as CCs compared with $13 \%$ of the other UCs (significant $\mathrm{P}<0.001$ ).

\section{Bronchitis}

Bronchitis occurred on 716 certificates, 433 times as the UC and 283 times as a CC. Of the CCs, $57 \%$ were associated with heart diseases as the UC, particularly ischaemic heart disease (table 3). There were 469 CCs associated with the $433 \mathrm{UCs}$ of bronchitis; $41 \%$ were heart disease, in particular congestive heart disease.

\section{VARIATION BY AGE}

The accuracy of recording of cause of death decreases with increasing age at death, particularly after 75 years old. ${ }^{24}$ Table 4 gives the number of TCs, UCs, and the ratio of TCs: UCs, for selected causes of death and different ages at death of the total study population.

Table 3 Distribution of UCs for which selected disease groups were CCs for total study population ( $n(\%))$

\begin{tabular}{|c|c|c|c|c|c|c|c|c|c|c|}
\hline \multirow[b]{2}{*}{$C C s$} & \multicolumn{10}{|l|}{$U C$} \\
\hline & $\begin{array}{l}\text { Malignant } \\
\text { neoplasms }\end{array}$ & Diabetes & $\begin{array}{l}\text { Cerebrovascular } \\
\text { disease }\end{array}$ & $\begin{array}{l}\text { Ischaemic } \\
\text { heart } \\
\text { disease }\end{array}$ & $\begin{array}{l}\text { Diseases of } \\
\text { arteries }\end{array}$ & $\begin{array}{l}\text { Other heart } \\
\text { and circulatory } \\
\text { disease }\end{array}$ & Pneumonia & Bronchitis & Other & Total \\
\hline $\begin{array}{l}\text { Malignant neoplasm } \\
\text { Diabetes } \\
\text { Cerebrovascular disease } \\
\text { Ischaemic heart disease } \\
\text { Diseases of arteries } \\
\text { Other heart and circulatory } \\
\text { disease }\end{array}$ & $\begin{array}{r}52(30) \\
27(14) \\
36(17) \\
48(16) \\
6(1) \\
107(5)\end{array}$ & $\begin{array}{r}0(0) \\
-9(4) \\
25(8) \\
8(1) \\
18(1)\end{array}$ & $\begin{array}{c}7(4) \\
36(19) \\
-\quad \\
55(18) \\
155(17) \\
90(5)\end{array}$ & $\begin{array}{r}65(37) \\
73(38) \\
59(28) \\
-\quad \\
633(71) \\
1089(55)\end{array}$ & $\begin{array}{r}4(2) \\
3(2) \\
4(2) \\
19(6) \\
-\quad 124(6)\end{array}$ & $\begin{array}{l}16(9) \\
11(6) \\
30(14) \\
38(13) \\
42(5) \\
-\end{array}$ & $\begin{array}{l}20(11) \\
14(7) \\
34(16) \\
17(6) \\
20(2) \\
48(2)\end{array}$ & $\begin{array}{r}4(2) \\
4(2) \\
7(3) \\
25(8) \\
3(0) \\
159(8)\end{array}$ & $\begin{array}{c}6(3) \\
24(12) \\
32(15) \\
71(24) \\
27(3) \\
350(18)\end{array}$ & $\begin{array}{r}174 \\
192 \\
211 \\
298 \\
894 \\
1985\end{array}$ \\
\hline $\begin{array}{l}\text { Pneumonia } \\
\text { Bronchitis }\end{array}$ & $\begin{array}{r}324(30) \\
33(12)\end{array}$ & $\begin{array}{l}14(1) \\
1(0 \cdot 4 \%)\end{array}$ & $\begin{array}{c}198(18) \\
23(8)\end{array}$ & $\begin{array}{c}81(7) \\
127(45)\end{array}$ & $\begin{array}{r}15(1) \\
9(3)\end{array}$ & $\begin{array}{l}50(5) \\
26(9)\end{array}$ & $\overline{17}(6)$ & $116(11)$ & $\begin{array}{r}294(27) \\
47(17)\end{array}$ & $\begin{array}{r}1092 \\
283\end{array}$ \\
\hline
\end{tabular}


Table 4 Mentions of TCs, UCs and ratio of TCs:UCs by age at death for selected causes of death, for the total study population

\begin{tabular}{|c|c|c|c|c|c|c|c|c|c|c|c|c|}
\hline \multirow[b]{3}{*}{ Disease } & \multicolumn{4}{|l|}{$15-64$} & \multicolumn{4}{|l|}{$65-74$} & \multicolumn{4}{|c|}{$\geqslant 75$} \\
\hline & \multirow[b]{2}{*}{$T C s$} & \multirow[b]{2}{*}{ UCs } & \multicolumn{2}{|c|}{ Ratio of TCs:UCs } & \multirow[b]{2}{*}{$T C s$} & \multirow[b]{2}{*}{ UCs } & \multicolumn{2}{|c|}{ Ratio of TCs:UCs } & \multirow[b]{2}{*}{$T C s$} & \multirow[b]{2}{*}{ UCs } & \multicolumn{2}{|c|}{ Ratio of TCs:UCs } \\
\hline & & & Study & $E$ and $W 1986$ & & & Study & $E$ and $W 1986$ & & & Study & $E$ and $W 1986$ \\
\hline \multicolumn{13}{|l|}{ Malignant neoplasms: } \\
\hline Stomach & & 179 & 1.03 & 1.06 & 96 & 92 & 1.04 & 1.08 & 36 & 31 & $1 \cdot 16$ & $1 \cdot 10$ \\
\hline Intestine & 109 & 105 & 1.04 & 1.05 & 66 & 55 & $1 \cdot 20$ & $1 \cdot 12$ & 29 & 26 & $1 \cdot 12$ & $1 \cdot 21$ \\
\hline Rectum & 68 & 62 & $1 \cdot 10$ & 1.05 & 50 & 47 & 1.06 & $1 \cdot 16$ & 21 & 17 & $1 \cdot 24$ & $1 \cdot 22$ \\
\hline Lung & 515 & 507 & 1.02 & 1.03 & 409 & 388 & 1.05 & 1.06 & 139 & 137 & 1.01 & 1.07 \\
\hline Prostate & 46 & 43 & 1.07 & $1 \cdot 10$ & 81 & 68 & $1 \cdot 19$ & $1 \cdot 16$ & 76 & 60 & $1 \cdot 27$ & $1 \cdot 27$ \\
\hline Diabetes & 86 & 27 & $3 \cdot 19$ & $3 \cdot 26$ & 109 & 24 & $4 \cdot 54$ & 3.35 & 63 & 15 & $4 \cdot 20$ & $2 \cdot 81$ \\
\hline Cerebrovascular disease & 406 & 336 & $1 \cdot 21$ & 1.45 & 423 & 334 & $1 \cdot 27$ & 1.38 & 236 & 184 & $1 \cdot 28$ & $1 \cdot 31$ \\
\hline Ischaemic heart disease & 1931 & 1813 & 1.07 & 1.56 & 1188 & 1074 & $1 \cdot 11$ & 1.58 & 551 & 485 & $1 \cdot 14$ & 1.56 \\
\hline Disease of the arteries & 558 & 87 & $6 \cdot 41$ & $4 \cdot 64$ & 442 & 137 & $3 \cdot 23$ & $3 \cdot 44$ & 195 & 77 & 2.53 & 3.00 \\
\hline Pneumonia & 438 & 95 & $4 \cdot 52$ & $9 \cdot 71$ & 564 & 163 & 3.46 & 9.96 & 489 & 139 & 3.52 & $5 \cdot 22$ \\
\hline Bronchitis & 318 & 190 & 1.67 & 2.63 & 282 & 173 & 1.63 & $2 \cdot 61$ & 116 & 70 & 1.66 & $2 \cdot 32$ \\
\hline
\end{tabular}

$\mathrm{E}$ and $\mathrm{W}=$ England and Wales.

The corresponding ratios for England and Wales 1986 are also given. ${ }^{25}$

In general, the ratios are of a similar order for malignant neoplasms within the two populations and tend to show the same trendsthat is, a slight increase in the ratios as the age at death increases-particularly for malignant neoplasm of the prostate. For many of the non-malignant disease groups the patterns across the age groups are again similar in the two populations, although there is no downward trend in the refinery population for cerebrovascular disease. The lower ratios for the total study population compared with those of England and Wales for cerebrovascular disease, ischaemic heart disease, pneumonia, and bronchitis (table 2) are also reflected across the age groups.

VARIATION BY DATE OF DEATH

There has been some suggestion that death certificates are more complete for multiple causes of death in the 1970s and 1980s than previously (Goldblatt, personal communication). Table 5 gives the ratio of TCs:UCs mentioned for selected causes of death separately for the $1950 \mathrm{~s}, 60 \mathrm{~s}, 70 \mathrm{~s}$ and $80 \mathrm{~s}$. In the refinery study there is a tendency for the ratio of TCs:UCs to increase for many disease groups over the 40 years covered by the study. This may of course partly be an artifact of the ageing process of the refinery cohort, with certificates of the elderly having more causes. Many of the ratios are of a similar order to those available for the population from England and Wales and show similar trends.
VARIATION BY OCCUPATION

Limited information on occupation was collected for the cohort-namely, last job for those who had left and current job for those still in employment. Full work history was not collected. Any analysis by occupation must therefore be treated circumspectly. Analyses by last job have been reported. ${ }^{22}$ Raised mortality patterns were found for some refinery, job, and disease combinations, but only one job group (labourers) showed raised mortality overall from several non-malignant diseases such as cerebrovascular disease, ischaemic disease, pneumonia, bronchitis, emphysema, and from malignant neoplasms of the stomach and lung. An examination of the ratios of TCs:UCs for labourers for these causes of death showed that they were of a similar order to those of the total study population.

SPECIFIC DISEASES

In the previously reported results, ${ }^{22}$ some raised mortality patterns in certain diseases and subgroups were identified. The following sections examine the contributory causes for two of these findings.

\section{Pneumonia}

In the analyses previously reported, ${ }^{22}$ some excesses of observed deaths compared with expected were found for specific disease groups and subgroups of the study population defined by refinery or by occupation. Routine examination of both the UC and CCs of these disease groups could provide a possible plausible explanation for some of these excesses if,

Table 5 Mentions of TCs, UCs and ratio of TCs:UCs by calendar period of death, for selected causes of death for the total study population

\begin{tabular}{|c|c|c|c|c|c|c|c|c|c|c|c|c|c|c|c|}
\hline & \multicolumn{3}{|c|}{$1951-60$} & \multicolumn{4}{|c|}{$1961-70$} & \multicolumn{4}{|c|}{$1971-80$} & \multicolumn{4}{|c|}{$1981-9$} \\
\hline & $T C s$ & UCs & $\begin{array}{l}\text { Ratio of } \\
\text { TCs:UCs } \\
\text { Study }\end{array}$ & $T C s$ & $U C s$ & $\begin{array}{l}\text { Ratio of } \\
\text { TCs:UCs } \\
\text { Study }\end{array}$ & $\begin{array}{l}\text { E and W } \\
1967 \\
\text { sample }\end{array}$ & $T C s$ & $U C s$ & $\begin{array}{l}\text { Ratio of } \\
\text { TCs:UCs } \\
\text { Study }\end{array}$ & $\begin{array}{l}E \text { and } W \\
1976\end{array}$ & $T C s$ & $U C s$ & $\begin{array}{l}\text { Ratio of } \\
\text { TCs:UCs } \\
\text { Study }\end{array}$ & $\begin{array}{l}E \text { and } W \\
1986\end{array}$ \\
\hline $\begin{array}{l}\text { Malignant } \\
\text { neoplasm of } \\
\text { lung }\end{array}$ & 73 & 73 & 1.00 & 186 & 183 & 1.02 & 1.03 & 381 & 366 & 1.04 & 1.05 & 423 & 410 & 1.03 & 1.05 \\
\hline $\begin{array}{l}\text { Diabetes } \\
\text { Cerebrovascular } \\
\text { disease }\end{array}$ & $\begin{array}{r}9 \\
88\end{array}$ & $\begin{array}{r}4 \\
76\end{array}$ & $\begin{array}{l}2 \cdot 25 \\
1 \cdot 16\end{array}$ & $\begin{array}{r}42 \\
222\end{array}$ & $\begin{array}{r}10 \\
188\end{array}$ & $\begin{array}{l}4 \cdot 2 \\
1 \cdot 18\end{array}$ & $\begin{array}{l}3.44 \\
1.18\end{array}$ & $\begin{array}{r}77 \\
377\end{array}$ & $\begin{array}{r}12 \\
293\end{array}$ & $\begin{array}{l}6 \cdot 42 \\
1 \cdot 29\end{array}$ & $\begin{array}{l}4.55 \\
1.36\end{array}$ & $\begin{array}{l}130 \\
378\end{array}$ & $\begin{array}{r}40 \\
297\end{array}$ & $\begin{array}{l}3 \cdot 25 \\
1 \cdot 27\end{array}$ & $\begin{array}{l}3.05 \\
1.35\end{array}$ \\
\hline $\begin{array}{l}\text { Ischaemic heart } \\
\text { disease }\end{array}$ & 244 & 234 & 1.04 & 722 & 675 & 1.07 & $2 \cdot 07^{\star}$ & 1234 & 1143 & 1.08 & $1 \cdot 11$ & 1470 & 1320 & $1 \cdot 11$ & $1 \cdot 46$ \\
\hline $\begin{array}{l}\text { Pneumonia } \\
\text { Bronchitis } \\
\text { All causes }\end{array}$ & $\begin{array}{r}66 \\
93 \\
1527\end{array}$ & $\begin{array}{r}20 \\
57 \\
890\end{array}$ & $\begin{array}{l}3.30 \\
1.63 \\
1.72\end{array}$ & $\begin{array}{r}240 \\
202 \\
3643\end{array}$ & $\begin{array}{r}73 \\
131 \\
2071\end{array}$ & $\begin{array}{l}3.29 \\
1.54 \\
1.76\end{array}$ & $\begin{array}{l}4 \cdot 14 \dagger \\
\text { N/A } \\
3 \cdot 57\end{array}$ & $\begin{array}{r}551 \\
263 \\
6101\end{array}$ & $\begin{array}{r}173 \\
153 \\
3289\end{array}$ & $\begin{array}{l}3.18 \\
1.72 \\
1.85\end{array}$ & $\begin{array}{l}2 \cdot 77 \\
1 \cdot 76 \\
\text { N/A }\end{array}$ & $\begin{array}{r}634 \\
158 \\
7228\end{array}$ & $\begin{array}{r}133 \\
92 \\
3878\end{array}$ & $\begin{array}{l}4 \cdot 77 \\
1 \cdot 72 \\
1 \cdot 86\end{array}$ & $\begin{array}{l}6 \cdot 20 \\
2 \cdot 28 \\
2 \cdot 27\end{array}$ \\
\hline
\end{tabular}

*4201 ICD-7; †Broncopneumonia only. $E$ and $W=$ England and $W$ ales. 
for example, compared with other refineries there was a difference in certification practice. It has been noted earlier that there seemed to be over-reporting of pneumonia as a UC in the refinery population compared with that of England and Wales. This occurred particularly in one refinery, where there was an excess of deaths from pneumonia compared with those expected. Twelve of these certificates had bronchopneumonia in part I (a) of the certificate and a malignancy in part II. The certifying doctors were all different. All of the deaths occurred in hospital. Eight occurred in one particular hospital. It should be noted that in the United Kingdom pneumonia is more often recorded as the UC in hospitals than elsewhere, for example, in $1976,79 \%$ of pneumonia deaths occurred in hospital compared with $58 \%$ of all deaths. ${ }^{26}$

\section{Aortic aneurysm}

In both the first and second follow ups of the cohort, excesses from diseases of the arteries (ICD 440-449) were reported in several refineries and job groups and at all ages $>60 . .^{2022} \mathrm{~A}$ further analysis at the second follow up showed that this was due to an excess of aortic aneurysms (ICD 441), of which $66 \%$ were ruptured. In $29 \%$ (54) of the 187 cases where aortic aneurysms was the UC this was the only cause on the death certificate, compared with $8 \%$ of the other causes that made up the group diseases of the arteries. Of the remaining 133 certificates with aortic aneurysm as the UC, the most common CCs were haemorrhage (43) and generalised arteriosclerosis (48). There were also 14 mentions of ischaemic heart disease, only one of myocardial infarction, 19 of hypertensive disease, and 28 of other heart disease (ICD 420-429). There were 33 deaths where aortic aneurysm was a CC; eight were ruptured. A third of these 33 deaths had a UC of ischaemic heart disease. There were six deaths where the UC was another disease in the diseases of the arteries group, four had a UC of generalised arteriosclerosis with a CC of ruptured aortic aneurysm. This result might indicate the wrong positioning of the UC on the death certificate by the certifying physician.

\section{Discussion}

The examination of multiple causes of death uses all available information on cause of death and throws light on results obtained with the UC only. For disease groups where excesses of observed deaths (based on UCs) compared with the expected on the basis of national rates have been found, investigation of both the UCs and CCs of the specific diseases by age, calendar period of death, region of residence, place of death, and certifying doctor may provide explanations for the excesses. For example, some of the excesses may have been the result of differences in the assignment of the UC, either at diagnosis or in completion of the certificate in particular areas and hospitals, or by particular certifying doctors, compared with the standard popula- tion, as in the excesses found where UCs only were used for pneumonia.

Three quarters of the death certificates of the refinery population had two or more causes. Dorn and Moriyama found $50 \%{ }^{8}$ and Guralnick found $58 \%$ in studies of American death certificates. A comparison of multiple cause patterns in California between 1955 and 1980 found an increase from $64-83 \%$ in the percentage of certificates with two or more causes. $^{3}$ Unlike the oil refinery study these studies count multiple mentions of causes from the same ICD " $A$ " list diagnostic group as a single occurrence, for example bronchitis (ICD-9 491) and emphysema (ICD-9 492). Since the late 1960 s about $80 \%$ of death certificates in England and Wales have had two or more causes of deaths mentioned. ${ }^{27}$

A matrix of UCs by CCs incorporates many previously used statistics of multiple causes analysis such as the frequency of the primary cause of death, and the ratio of frequencies of UCs:CCs for a particular cause. Routine calculation of these ratios in an occupational mortality study and those of the chosen comparison population would indicate differences in assignment of the UC. Multiple cause coding has been carried out on samples of death certificates by OPCS since 1972 and unpublished tabulations of UCs and CCs by sex and age are available for England and Wales, and the regional health authorities. These could provide a useful comparison for multiple cause analysis in occupational mortality studies, as, although incomplete, death rates for total occurrences of specific diseases or for particular combinations of diseases could be estimated with these tabulations.

The increasing use of multiple causes has the practical implication that it becomes more difficult to decide the UC. Changes in World Health Organisation (WHO) rules for the selection of the UC may also affect the number of deaths assigned to a particular UC; for example, a change in 1984 to allow, under some circumstances, the selection of the UC from part II of the certificate had the effect of reducing the number of deaths ascribed to some common terminal effects, such as cerebrovascular disease, and increasing the number due to some chronic disorders, such as diabetes. ${ }^{27}$ There is no evidence to suppose that there is a difference in coding practice between the refinery study and England and Wales.

Where the ratios of TCs:UCs mentioned are lower in a study population than the comparison population used as standard, this implies proportionately more study certificates with these diseases coded as UC than CC. This is important for the interpretation of the standardised mortality ratios (SMR) based on the UC when, as in this refinery study the national population is used for comparison, an excess of observed deaths is thus more likely to be found.

As full work history was not collected analysis by occupation was limited. An examination of the multiple causes of death for labourers, a job group that showed 
consistently raised mortality when UCs were analysed, gave no indication that there was any difference between labourers and the rest of the study population, in either the number or distribution of causes recorded. It has previously been discussed that adjustment of the rates because of the higher mortality of labourers in the general United Kingdom population would have partially removed some of the excess mortality. ${ }^{22}$ In contrast, pneumonia was found to be reported more as a $\mathrm{UC}$ in the refinery population than in the general population in England and Wales. Analyses of the multiple causes associated with pneumonia in the refinery population suggested that the previously reported excesses may be due to different practices in assigning the UC.

The finding of an excess of deaths from aortic aneurysm in the analyses by UC only was unexpected and difficult to interpret. ${ }^{22}$ There had been no previous evidence from refinery studies of an association within the oil industry, although Schnatter et al reports an excess of deaths from aortic aneurysm in Canadian oil distribution workers. ${ }^{28}$ The examination of the multiple causes of this disease showed that in just under a third of certificates this was the only cause on the certificate. Many of the CCs were in the heart disease groups. Investigation of these did not provide evidence that there had been either miscoding or inappropriate positioning of causes that might have resulted in a misleading excess when only the UC was used.

As well as those uses discussed in this paper, matrices of UCs by CCs could be used to facilitate the examination of proportional mortality ratios (PMR) by cause of death, as suggested by Wong et al. ${ }^{9}$ The ratio of the diagonal entry to the sum of the diagonal elements is equivalent to a PMR where no adjustment has been made for age. It can be age adjusted by the use of similar ratios from some standard population. This could be further extended to obtain an estimation of competing risk - that is, the risk of dying from one disease rather than another. ${ }^{29-31}$

The results from this refinery cohort have drawn attention to the association of specific diseases - for example, cancers and pneumonia, diabetes and strokes, ischaemic heart disease and arteriosclerosis, bronchitis and congestive heart disease. Guralnick suggested that it may be useful to retain each death rather than each cause as a unit of tabulation, and to extend the causes examined to combinations of diseases reported together on each record. ${ }^{5}$ This process can, of course, become rapidly cumbersome, with a large number of possible combinations of causes. It also poses the problem of whether disease $A$ as the UC with disease $B$ as the $C C$ should be treated in the same way as disease $A$ as the $C C$ and disease $B$ as the UC. The above analyses suggest that this may be appropriate for some specific disease combinations, especially if tabulations are also available for a comparison population. Both Guralnick ${ }^{5}$ and Chamblee and Evans $^{2}$ suggest tabulating the presence and absence of two diseases to investigate their possible association.

The accuracy and completion of death certificates have been extensively studied. ${ }^{32} 33$ In the comparison of an occupational cohort with the national population, whether the UC only or multiple causes are examined-for example, comparing ratios of TCs:UCs-it has to be assumed that any inaccuracies are similar in both populations, unless there is good evidence to the contrary. An examination of regional variations and a knowledge of local practices may help to elucidate this. The analysis described above, of the deaths from pneumonia at one particular refinery, is an example. Although limited, examination of the CCs of death certificates of an industrial cohort may throw light on the non-fatal disease in the industry, especially if these are different from the national data. The number of CCs recorded on a death certificate varies considerably depending on such factors as the UC, the age of the decedent, and the place of death, and it is doubtful whether a reliable estimate of non-fatal disease in a study group could be obtained from CCs alone.

The proportion of certificates with more than one disease mentioned is higher at older ages for all causes of death taken together. There has been a suggestion that a single cause of death is less clearly identifiable in the elderly, and that a combination of several diseases may contribute to the death. ${ }^{24}$ These results also emphasise the problems of identifying a single specific UC of death at older age groups and in the circulatory system disease groups in particular.

Examination of the CCs can be used to identify cases that may eventually have had a fatal outcome if another cause had not intervened. This is particularly useful in nested case-control studies in which deaths from a particular disease are matched with controls from the rest of the study population. For example, as previously reported, raised mortality with the UC was found in malignant neoplasm of the kidney for oil distribution workers. ${ }^{34}$ The ratio of TCs:UCs mentioned for this population were higher than that for England and Wales, which suggests either a possible under-reporting of this disease as a UC or over-reporting as a CC. In the case of under-reporting of the UCs this would perhaps strengthen concern about the raised mortality. A nested case-control study is planned to investigate exposures for kidney cancer. In this situation, however, the identification of additional cases through the CCs depends, once again, on the disease firstly being diagnosed, and secondly being thought to be of sufficient importance by the certifying doctor to be entered on the death certificate.

In conclusion, useful additional information can be obtained in the analysis of an industrial cohort from an examination of the multiple causes of death. The interpretation of positive findings in a standard cohort analysis of UCs can be hindered if these are partly due to miscoding or a wrong positioning of the UC. An examination of the multiple 
causes can identify such occurrences and can highlight different local practices of certification. The comparisons of ratios of TCs:UCs in a cohort with those in a standard population can also aid identification of true associations. Multiple cause analysis gives limited information on the morbidity of a cohort and may draw attention to the association of specific diseases. An important use of the multiple causes is the identification of additional cases of specific diseases for use in nested case-control studies. Selection of cases based on both UCs and CCs increases the sample size and hence the power. Also the selection of controls based on both UC and CC-that is, with no mention of the disease on the death certificate at all-makes the case-control classification based on mortality data more appropriate, as individuals with the disease as a CC would not be eligible. It is thus recommended that, where possible, CCs of death should be coded routinely in cohort studies. Analyses such as those reported in this paper are straightforward to carry out and can only add to results obtained with the UC only.

The sponsorship of the Institute of Petroleum, and the provision of death certificates by the Office of Population Censuses and Surveys are gratefully acknowledged.

1 Alderson MR. Central government routine health statistics. In: Maunder WF, ed. Reviews of United Kingdom tics. In: Maunder WF, ed. Reviews of United

2 Chamblee RF, Evans MC. New dimensions in cause of death statistics. Am $\mathcal{F}$ Public Health 1982;72:1265-70.

3 White MC, Selvin S, Merrill DW. A study of multiple causes of death in California: 1955 and 1980. F Clin Epidemiol 1989;42:355-65.

4 Milham S. Using multiple cause of death coding in occupational mortality studies. Am $\mathcal{f}$ Ind Med 1988;14: 341-4.

5 Guralnick L. Some problems in the use of multiple causes of death. Fournal of Chronic Diseases 1966;19:979-90.

6 Cohen J, Steinitz R. Underlying and contributory causes of death of adult males in two districts. Fournal of Chronic Diseases 1969;22:17-24

7 Weiner L, Bellows MT, McAvoy GH, Cohen EV. Use of multiple causes in the classification of deaths from carmultiple causes in the classification of deaths from cardiovascular

8 Dorn HF, Moriyama IM. Uses and significance of multiple cause tabulations for mortality statistics. $A m \mathcal{F}$ Public Health 1964;54:400-6.

9 Wong O, Rockette HE, Redmond CK, Heid M. Evaluation of multiple causes of death in occupational mortality studies. Fournal of Chronic Diseases 1978;31: 183-93.
10 OPCS. 1979 Mortality Statistics Cause. London: HMSO, 1980. (Series DH2 No 6.)

11 Manton KG, Stallard E. Temporal trends in US multiple cause of death mortality data: 1968 to 1977 . Demography 1982:19.527-47.

12 Wing S, Manton KG. The contribution of hypertension to mortality in the US: 1968, 1977. Am F Public Health 1983;73:140-4.

13 Israel RA, Rosenberg HM, Curtin LR. Analytical potential for multiple cause-of-death data. Am $\mathfrak{F}$ Epidemiol 1986;124:161-79.

14 Puffer RR. New approaches for epidemiologic studies of mortality statistics. Bull PAHO 1989;23:365-83.

15 Heasman MA, Lipworth L. GRO studies on medical and population subjects. No 20. Accuracy of certification of cause of death. London: HMSO, 1990.

16 Cameron HM, McGoogan E, Watson H. Necropsy: a yardstick for clinical diagnoses. $B M \mathcal{F} 1980 ; 281: 985-8$.

17 Kircher T, Nelson J, Burdo $H$. The autopsy as a measure of accuracy of the death certificate. $N$ Engl $f$ Med accuracy of the

18 Moriyama IM, Baum WS, Haenszel WM, Mattison BF. Inquiry into diagnostic evidence supporting medical certifications of death. Am $\mathcal{F}$ Public Health 1958;48: 1376-87.

19 Reid DD, Rose GA. Assessing the comparability of mortality statistics. $B M \mathcal{F} 1964 ; 2: 1437-9$.

20 Rushton L, Alderson MR. An epidemiological survey of eight oil refineries in Britain. Br f Ind Med 1981;38: 225-34.

21 Case RAM, Coghill C, Davies JM, et al. Serial mortality tables. Neoplastic diseases vol 1, England and Wales, 1911-1970. London: Institute of Cancer Research, 1976.

22 Rushton L. Further follow up of mortality in a United Kingdom oil refinery cohort. $B r \mathcal{F}$ Ind Med 1993;50: 549-60.

23 Rushton L. The Institute of Petroleum epidemiological study. Refinery study principal results 1951-1989. London: Institute of Petroleum, 1991.

24 James G, Patton RE, Heslen A. Accuracy of cause-ofdeath statements on death certificates. Public Health Rep 1955;70:39-51.

25 Office of Population Censuses and Surveys. 1986 Mortality statistics cause. London: HMSO, 1988. (Series DH2 No 13.)

26 Office of Population Censuses and Surveys. Mortality statistics 1976. London: HMSO, 1978. (Series DH1 No 4.)

27 Ashley J, Devis T. Death certification from the point of view of the epidemiologist. In: Population Trends No 67. London: HMSO, 1992

28 Schnatter AR, Katz AM, Nicolich MJ, Theriault G. A retrospective mortality study among Canadian petroleum marketing and distribution workers. Environ Health Perspect 1993;101:85-99.

29 Chiang CL. Competing risks and conditional probabilities. Biometrics 1970;26:767-76.

30 Hoel DG. A representation of mortality data by competing risks. Biometrics 1972;28:475-88.

31 Wong $\mathrm{O}$. A competing risk model based on the life table procedure in epidemiological studies. Int $\mathcal{F}$ Epidemiol 1977;6:153-9.

32 Royal College of Physicians and Royal College of Pathologists. Medical aspects of death certification. f Royal Coll Physicians Lond 1981;16:205-18

33 Gobbato F, Vecchiet F, Barbierato D, Melato M, Manconi R. Inaccuracy of death certificate diagnoses in malignancy: an analysis of 1405 autopsied cases. Hum Pathol 1982;13:1036-8.

34 Rushton L. A 39 year follow-up of the UK oil refinery and distribution centre studies: results for kidney cancer and leukaemia. Environ Health Perspect Suppl 1993; 101(suppl 6):77-84. 